\title{
Complexation of Bis-2-(benzylideneamino)Phenol to Cobalt(II) and Zinc(II), and their Spectroscopic Studies
}

\author{
MENG GUAN TAY* ${ }^{1}$, ZAINAB NGAINI $^{1}$, MAYA ASYIKIN MOHD ARIF ${ }^{1}$, \\ NORAZILAWATI MUHAMAD SARIH ${ }^{2}$, WAN M. KHAIRUL ${ }^{3}$, SIU PING LAU ${ }^{1} \&$ \\ EMELIA ENGGIE ${ }^{1}$
}

\begin{abstract}
${ }^{1}$ Department of Chemistry, Faculty of Resource Science and Technology, Universiti Malaysia Sarawak, 94300 Kota Samarahan, Sarawak, Malaysia. ${ }^{2}$ Department of Chemistry, Faculty of Science University of Malaya, 50603 Kuala Lumpur, Malaysia. ${ }^{3}$ Advanced Materials Research Group, Department of Chemical Sciences, Faculty of Science and Technology, Universiti Malaysia Terengganu, 21030 Kuala Terengganu, Terengganu, Malaysia
\end{abstract}

\begin{abstract}
A bis-Schiff base of bis-2-(benzylideneamino)phenol (SB1) was synthesized via condensation reaction of terephthaldehyde and 2-aminophenol in ethanol. SB1 was then reacted with respective $\mathrm{MX}_{2}$ salt $(\mathrm{M}=\mathrm{Co} \& \mathrm{Zn}$, $\mathrm{X}=\mathrm{Cl} \& \mathrm{OAc}$ ) in the ligand to metal ratio of 1:2 under refluxing condition in ethanolic $\mathrm{KOH}$ solution for six hours. All synthesized complexes were characterized using FT-IR and UV-vis spectroscopy. The formation of complexes with Co and Zn was indicated by the shifts observed from the IR peaks and $\lambda_{\max }$ of the UV absorption bands for the $\mathrm{C}=\mathrm{N}$ bond. The IR peak at $1621 \mathrm{~cm}^{-1}$ in $\mathrm{SB} 1$ was shifted to around 1638 and $1619 \mathrm{~cm}^{-1}$ after forming its complexes with $\mathrm{Co}$ and $\mathrm{Zn}$, respectively. The absorption band of $\mathrm{C}=\mathrm{N}$ bond was blue shifted from $\lambda_{\max }$ of $384 \mathrm{~nm}$ to $307 \mathrm{~nm}$ in Co(II) complex, whereas this band was red-shifted to $389 \mathrm{~nm}$ in the $\mathrm{Zn}$ (II) complex. Therefore, SB1 was confirmed to coordinate with the $\mathrm{Co}(\mathrm{II})$ and $\mathrm{Zn}(\mathrm{II})$ metal centres via the imine nitrogen.
\end{abstract}

Keywords: Bis-Schiff base, Co and Zn complexation

\section{INTRODUCTION}

Schiff base is considered as a very important class of organic compounds, which is commonly employed as versatile ligands in organic and inorganic synthesis due to its wide variety of applications such as in drugs, electronic devices and catalysis applications (Nishinaga et al., 1988; Tarafder et al., 2002; Ershad et al., 2009; Przybylski et al., 2009). Most studies of single substituted Schiff base compounds are mainly focused on the biological studies (Bagihalli et al., 2009; Kumar et al., 2010), whereas the studies of bisSchiff base analogues are normally mainly focused on the complexation (Park et al, 1998; Ortiz \& Park, 2000; Turan \& Sekerci, 2009). However, reports on bis-2-(benzylideneamino) phenol (SB1) (Figure 1) are still very scarce especially in the complexation study with transition metals.
Most Schiff base compounds used for complexation study are bidentate in nature, and the most common one is derived from the $o$ hydroxybenzaldehyde (Park et al, 1998; Cotton et al., 1999; Ortiz \& Park, 2000; Abd-Elzaher, 2001; Cozzi, 2004; Salavati-Niasari et al., 2005, Li et al., 2009). The coordination modes of this type of Schiff base ligands are usually through the nitrogen atom at the imine group and the oxygen atom from the hydroxyl at the ortho-position. IR spectroscopy is the most common and easiest method used for determination of the coordination mode of the complexes (Ebsworth et al., 1987; Crabtree, 1994; Ran et al., 2011). For Schiff base complexes, significant shift of the band of interest of the $\mathrm{C}=\mathrm{N}$ group in IR spectrum is clearly and commonly observed.

*Corresponding author:mgtay@frst.unimas.my 




Figure 1. Structure of bis-2-(benzylideneamino)phenol (SB1)

\section{MATERIALS \& METHODS}

\section{Materials and Characterizations}

Terephthaldehyde, 2-aminophenol, cobalt(II) chloride and zinc(II) acetate were obtained from Sigma Aldrich, Across and BDH, and used as received without further purification.

The infrared spectra were recorded on Perkin Elmer Spectrum GC Fourier-Transform Spectrometer using $\mathrm{KBr}$ disc. The ${ }^{1} \mathrm{H}$ NMR spectrum for SB1 was recorded on a JEOL ECA - $500 \mathrm{MHz}$ NMR relative to TMS as the internal standard and were referenced via residual proton NMR resonances of the appropriate deuterated solvent (DMSO- $\mathrm{d}_{6}: \delta_{\mathrm{H}}$ 2.50). All the UV-Vis absorption spectra were recorded on a Perkin-Elmer Lambda-40-UVVis spectrometer with a $1 \mathrm{~cm}$ quartz cuvette in the range of $200-800 \mathrm{~nm}$.

\section{Synthesis of bis-2-(benzylideneamino) phenol (SB1)}

2-aminophenol (2.18 g, 20 mmoles) and terephthaldehyde (1.34 g, 10 mmoles) were added into a beaker containing $25 \mathrm{~mL}$ of ethanol. The mixture was stirred at room temperature for $4 \mathrm{~h}$. Yellow solid was formed, filtered and dried. The yellow solid was recrystallized via slow diffusion from the mixture of dichloromethane and hexane. Yield 2.83 g, 89\%. m.p.: $220-221{ }^{\circ} \mathrm{C}$. UV $\left(\lambda_{\max }\right.$, $\mathrm{nm}): 300,384 .{ }^{1} \mathrm{H}$ NMR (DMSO-d ${ }_{6}, 500$ $\left.\mathrm{MH}_{\mathrm{Z}}\right), \delta_{\mathrm{H}}: 9.10(\mathrm{~s}, 1 \mathrm{H},-\mathrm{OH}), 8.80(\mathrm{~s}, 1 \mathrm{H},-$ $\mathrm{CH}=\mathrm{N}-), 8.16\left(\mathrm{~s}, 4 \mathrm{H},-\mathrm{CH}_{\text {arom }}\right), 7.26\left(\mathrm{~d}, 2 \mathrm{H}, J_{\mathrm{H}-}\right.$ $\left.\mathrm{H}=8 \mathrm{~Hz}, \mathrm{CH}_{\text {arom }}\right), 7.11\left(\mathrm{t}, 2 \mathrm{H}, J_{\mathrm{H}-\mathrm{H}}=8 \mathrm{~Hz}\right.$, $\left.\mathrm{CH}_{\text {arom }}\right), 6.92\left(\mathrm{~d}, 2 \mathrm{H}, J_{\mathrm{H}-\mathrm{H}}=8 \mathrm{~Hz}, \mathrm{CH}_{\text {arom }}\right), 6.86$ (t, $\left.2 \mathrm{H}, J_{\mathrm{H}-\mathrm{H}}=8 \mathrm{~Hz}, \mathrm{CH}_{\text {arom }}\right)$. IR $(\mathrm{KBr}): v_{\mathrm{OH}}=$ $3459, v_{\mathrm{C}=\mathrm{N}}=1621, v_{\mathrm{C}=\mathrm{C}}=1582 \& 1481, v_{\mathrm{C}-\mathrm{O}}=$ $1374 \mathrm{~cm}^{-1}$.

\section{Complexation of SB1 with $\mathrm{Co}(\mathrm{II})$ and $\mathrm{Zn}(\mathrm{II})$}

\section{General procedure}

SB1 (0.032 g, 0.1 mmoles) was dissolved in 20 $\mathrm{mL}$ of ethanol in Schlenk round bottom flask. Potassium hydroxide ( $0.012 \mathrm{~g}, 0.2$ mmoles) in $10 \mathrm{~mL}$ of ethanol was added drop wise to the SB1 solution. The colour of the mixture changed from yellow to orange. An ethanolic solution of $\mathrm{MX}_{2}$ salt $(0.2$ mmoles) [where $\mathrm{M}=$ $\mathrm{Co}^{2+}$ and $\mathrm{Zn}^{2+}, \mathrm{X}=\mathrm{Cl}^{-}$and $\mathrm{C}(\mathrm{O}) \mathrm{OCH}_{3}{ }^{-}$, respectively] was added dropwise into the resulting mixture. The mixture was refluxed for $6 \mathrm{~h}$ and allowed to cool to room temperature. The solvent was removed in vacuo to afford the product.

\section{Complexation of SB1 with Co(II), CoSB1}

Cobalt(II) chloride hexahydrate $(0.048 \mathrm{~g}, 0.2$ mmoles). Dark brown solids, weight: $0.06 \mathrm{~g}$. $\mathrm{UV}\left(\lambda_{\max }, \mathrm{nm}\right): 259,307,427$. IR $(\mathrm{KBr}): v_{\mathrm{O}-\mathrm{H}}=$ $3551, v_{\mathrm{C}=\mathrm{N}}=1638, v_{\mathrm{C}=\mathrm{C}}=1591 \& 1459, v_{\mathrm{C}-\mathrm{O}}=$ $1384, v_{\mathrm{Co}-\mathrm{N}}=584 \mathrm{~cm}^{-1}$.

\section{Complexation of SB1 with $\mathrm{Zn}(\mathrm{II}), \mathrm{ZnSB} 1$}

Zinc(II) acetate ( $0.051 \mathrm{~g}, 0.2$ mmoles). Reddish brown solids, weight: $0.06 \mathrm{~g}$. $\left(\lambda_{\max }, \mathrm{nm}\right): 296$, 389 , 475. IR (KBr): $v_{\mathrm{O}-\mathrm{H}}=3414, v_{\mathrm{C}=\mathrm{O}}=1695$, $v_{\mathrm{C}=\mathrm{N}}=1619, v_{\mathrm{C}=\mathrm{C}}=1583 \& 1472, v_{\mathrm{C}-\mathrm{O}}=1412$, $v_{\mathrm{Zn}-\mathrm{N}}=523 \mathrm{~cm}^{-1}$.

\section{RESULTS \& DISCUSSION}

\section{Spectroscopic characterization of SB1}

The yellow solid of SB1 was successfully synthesized from the reaction of terephthaldehyde with 2-aminophenol in 
alcoholic solution. The compound was recrystallized via slow diffusion from the mixture of dichloromethane and hexane to afford $89 \%$ yield. The formation of SB1 is shown in Scheme 1. Dipolar intermediate of terephthaldehyde was formed after reacting with aniline, followed by intramolecular electron rearrangement to produce aminoalcohol. SB1 was yielded through the elimination of two water molecules from aminoalcohol (Solomons \& Fryhle, 2011).

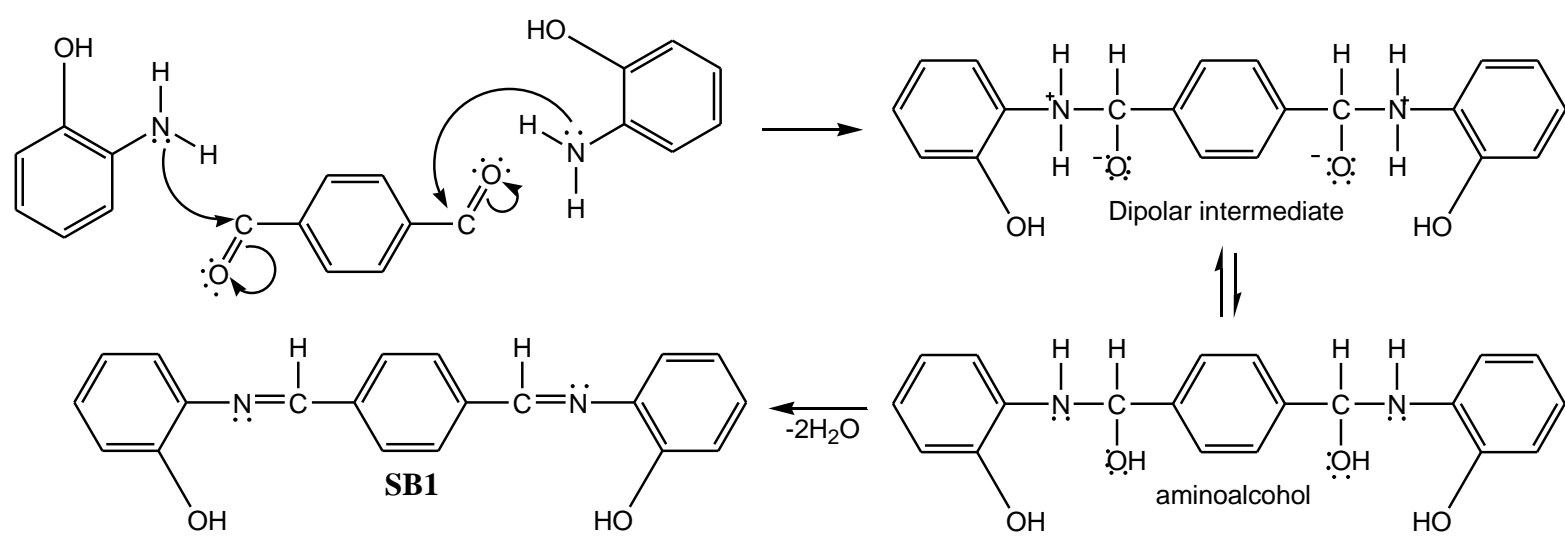

Scheme 1: Mechanism of the formation of SB1

The ${ }^{1} \mathrm{H}$ NMR spectrum of SB1 is shown in Figure 2. The formation of SB1 is indicated by the presence of the $\mathrm{C}=\mathrm{NH}$ resonance at $\delta_{\mathrm{H}} 8.80$ and the phenolic proton at $\delta_{\mathrm{H}} 9.10$. The four aromatic protons attributed to the middle aromatic group appeared as a singlet at $\delta_{\mathrm{H}} 8.16$.

The IR spectrum of SB1 is shown in Figure 3. The peak appeared at $1621 \mathrm{~cm}^{-1}$ was attributed to $\mathrm{C}=\mathrm{N}$ stretching of SB1. The intramolecular hydrogen bond between the hydroxyl group and the nitrogen atom in SB1 was observed at $3286 \mathrm{~cm}^{-1}$ with a broad $\mathrm{N}-\mathrm{H}$ stretching band (Patel et al., 2008). Indeed, this statement can be supported by a broad phenolic singlet at $\delta$ 9.10 in the ${ }^{1} \mathrm{H}$ NMR spectrum. 


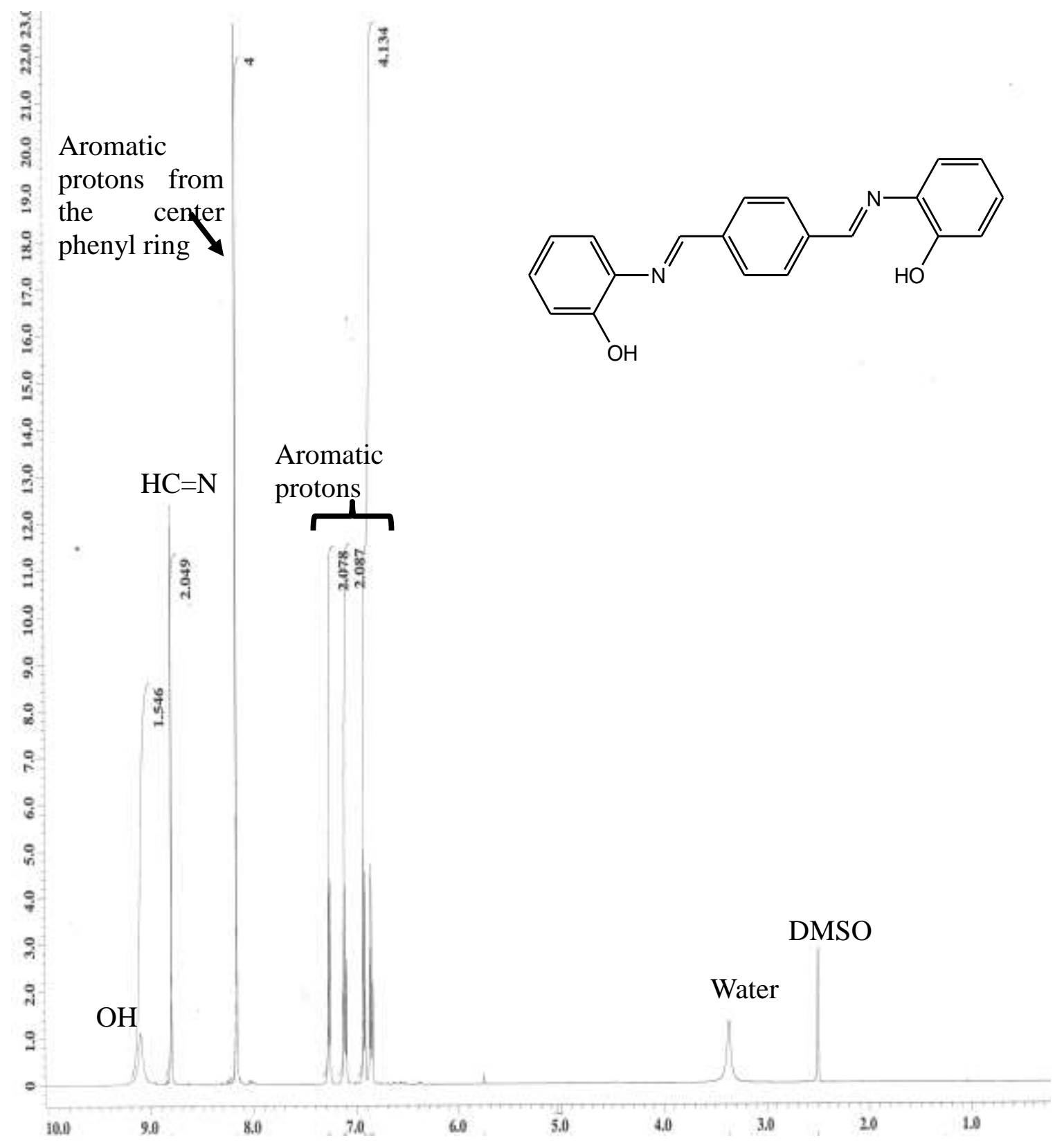

Figure 2. ${ }^{1} \mathrm{H}$ NMR spectrum of SB1 


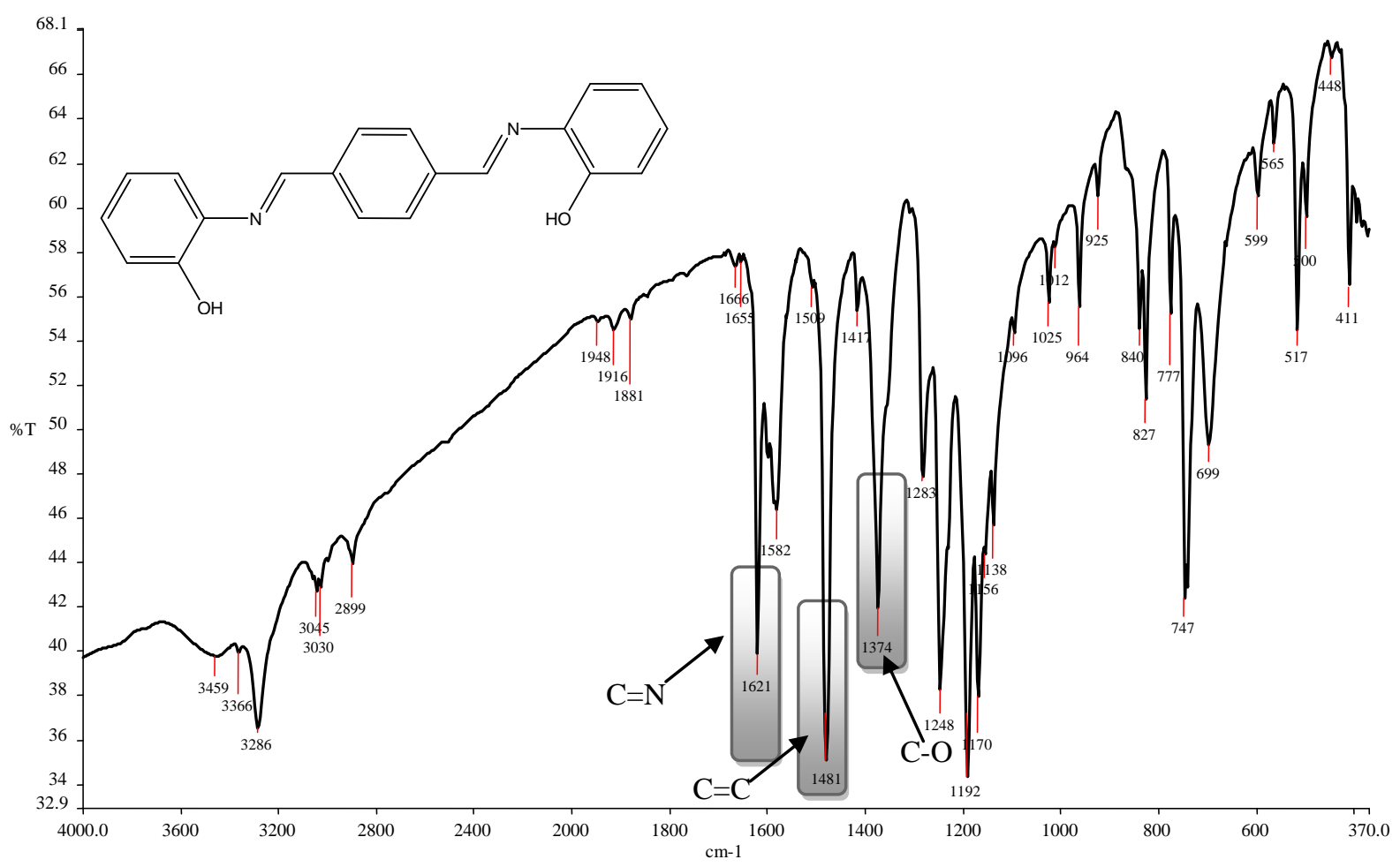

Figure 3. IR spectrum of SB1

The absorption spectrum of SB1 was recorded in DMSO at room temperature (Figure 4). Two absorption bands appeared at $\lambda_{\max }$ of 300 and
$384 \mathrm{~nm}$ which are believed to be due to the $\pi \rightarrow \pi^{*}$ transition of aromatic ring and $n \rightarrow \pi^{*}$ transition of imine group, respectively.



Figure 4. UV-Vis absorption spectrum of SB1 


\section{Complexation of SB1 with cobalt(II) and $\operatorname{zinc}($ II)}

The synthesized SB1 was reacted with cobalt(II) chloride and zinc(II) acetate, respectively, under refluxing condition for six hours. The ${ }^{1} \mathrm{H}$ NMR spectra of both complexes were not successfully obtained. For the CoSB1 complex, which was formed from the reaction of SB1 with cobalt(II) chloride, the shimming process was not responding during NMR analysis. This indicates that the Co complex is paramagnetic with the oxidation state of +2 . Whereas for ZnSB1 complex which was formed from the reaction of SB1 with zinc(II) acetate, the complex was insoluble in most common NMR solvents such as DMSO- $\mathrm{d}_{6}$ and $\mathrm{CDCl}_{3}$.

However, the structural studies of both complexes were preceded with IR spectroscopy. Figure 5 shows the IR spectra of CoSB1 and ZnSB1, whereas Table 1 shows the IR data of SB1, CoSB1 and ZnSB1. For CoSB 1 complex, the frequency of $\mathrm{C}=\mathrm{N}$ was shifted to a higher energy at $1638 \mathrm{~cm}^{-1}$, whereas for ZnSB1, the IR signal was shifted to a lower energy at $1619 \mathrm{~cm}^{-1}$. The difference between the IR shifts in both complexes can be explained based on the difference of electron density in the two metals. Zinc is full with electrons in its $d$ orbitals, and therefore the back-bonding from the zinc is much stronger than cobalt. The electrons back-bonded from the zinc fill up the antibonding $\pi^{*}$ orbital in $\mathrm{C}=\mathrm{N}$, and resulted a weaker bond of $\mathrm{C}=\mathrm{N}$. As a result, the $\mathrm{C}=\mathrm{N}$ energy was lowered in the IR spectrum (Ray et al., 2011; Maity et al., 2011). For CoSB1, the back-bonding effect from cobalt is not as strong as zinc because cobalt exhibits much electronegative behaviour than zinc (electronegativity values: cobalt $=1.9$; zinc $=1.7)$ and cobalt is not as electron rich as zinc. Due to high electronegativity of cobalt, the electron is withdrawn from the $\mathrm{C}=\mathrm{N}$ bond to the cobalt metal centre and resulted in a stronger $\mathrm{C}=\mathrm{N}$ bond. The phenolic $v(\mathrm{C}-\mathrm{O})$ stretching peak was observed to be shifted from $1374 \mathrm{~cm}^{-1}$ to $1384 \mathrm{~cm}^{-1}$ in CoSB1 and $1412 \mathrm{~cm}^{-1}$ in $\mathrm{ZnSB} 1$. This is due to electrons donation from oxygen to the metal centre, which simultaneously withdraws the electron from the $\mathrm{C}-\mathrm{O}$ bond, resulting in an increase in the bond energy of $\mathrm{C}-\mathrm{O}$. Moreover, the additional peaks in both IR spectra at 584 and $523 \mathrm{~cm}^{-1}$ in CoSB1 and ZnSB1, respectively, were attributed to $v(\mathrm{M}-\mathrm{N})$, which therefore support the formation of both complexes (Bhattacharjee et al., 2012). The $\mathrm{OH}$ absorption band found at the region of 3413 to $3448 \mathrm{~cm}^{-1}$ is believed to be due to the presence of water vapour from the surrounding environment during the IR analysis.

Table 1: IR data $\left(\mathrm{cm}^{-1}\right)$ of SB1, CoSB1 and $\mathrm{ZnSB} 1$

\begin{tabular}{llllll}
\hline Compounds & $v(\mathrm{C}=\mathbf{O})$ & $v(\mathrm{C}=\mathrm{N})$ & $v(\mathrm{C}=\mathrm{C})$ & $v(\mathrm{C}-\mathrm{O})$ & $v(\mathrm{M}-\mathrm{N})$ \\
\hline SB1 & - & 1621 & 1582,1481 & 1374 & - \\
CoSB1 & - & 1638 & 1591,1459 & 1384 & 584 \\
ZnSB1 & 1695 & 1619 & 1583,1472 & 1412 & 523 \\
\hline
\end{tabular}

Key: “_“ indicates no data. 


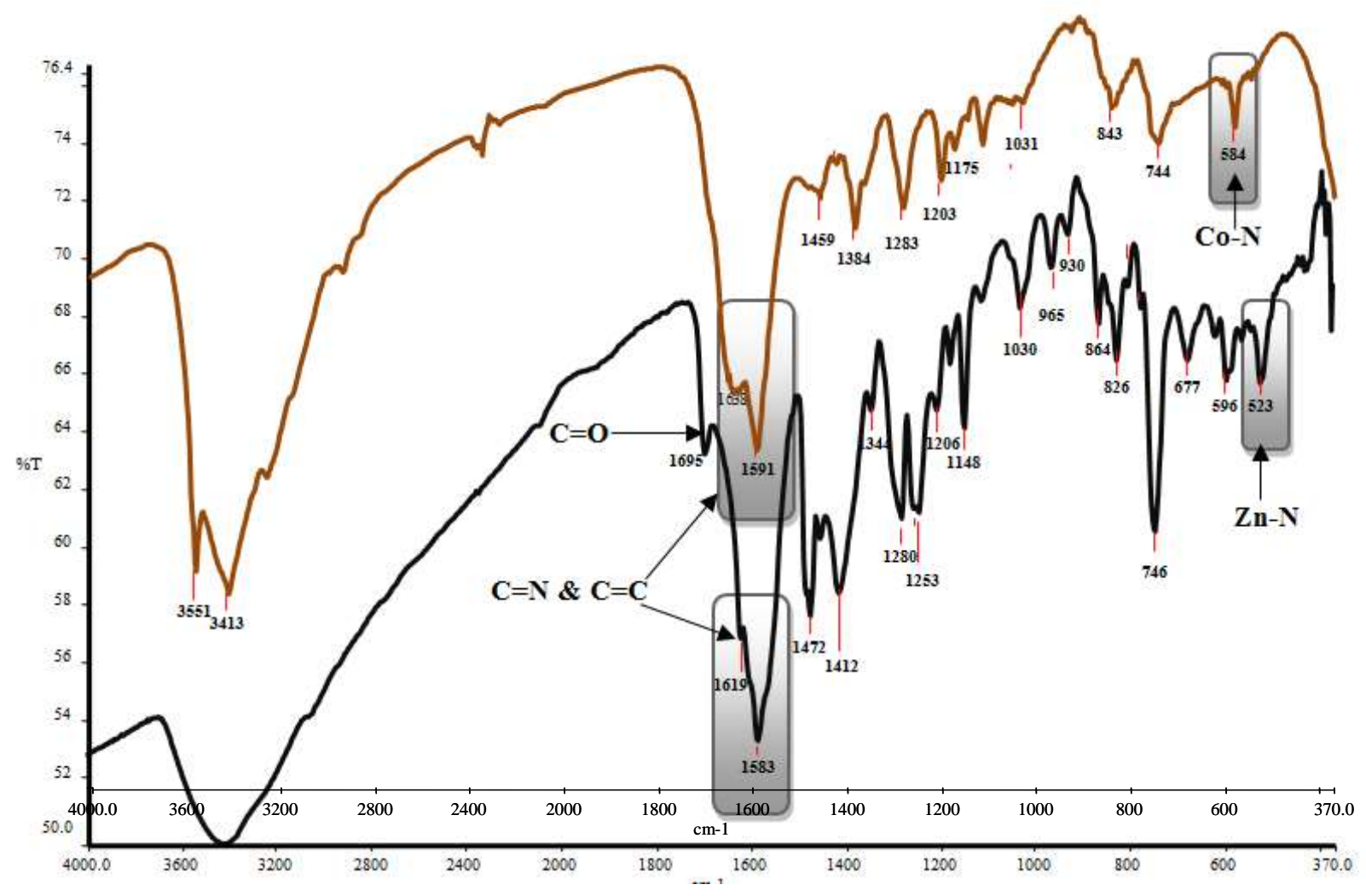

Figure 5. IR spectra of CoSB1 (top) and ZnSB1 (bottom)

The UV absorption spectra of CoSB1 and ZnSB1 were recorded in DMSO at room temperature (Figure 6). For CoSB1, the $n \rightarrow \pi^{*}$ absorption band of $\mathrm{C}=\mathrm{N}$ group was blue shifted to a shorter wavelength at $307 \mathrm{~nm}$, whereas the ZnSB1 complex showed bathochromic shift to longer wavelength at $389 \mathrm{~nm}$ compared to SB1 $(384 \mathrm{~nm})$. These absorption bands shifts support the IR results where the $\mathrm{C}=\mathrm{N}$ was strengthened in CoSB1 but it was weaken in ZnSB1. Both complexes exhibited an additional absorption band at $427 \mathrm{~nm}$ for CoSB1 and $475 \mathrm{~nm}$ for $\mathrm{ZnSB} 1$. This may be due to a metal-to-ligand charge transfer (MLCT) in the complex (Ran et al., 2011).


Figure 6. UV-Vis spectra of a) CoSB1 and b) ZnSB1 


\section{CONCLUSION}

SB1 successfully formed complexes with cobalt and zinc, respectively. Significant shifts were observed in the IR and UV spectra after the complexation reactions. Based on the IR results, the coordination of SB1 to the respective metal centers was confirmed to be via the imine nitrogen.

\section{ACKNOWLEDGMENTS}

We are grateful to the Ministry of Higher Education, Malaysia for the financial support through research grant FRGS/02(27)/770/2010(51).

\section{REFERENCES}

Abd-Elzaher, M. M. (2001). Spectroscopic characterization of some tetradentate Schiff bases and their complexes with nickel, copper and zinc. Journal Chinese Chemical Society, 48: 153-158.

Bagihalli, G. B., Patil, S. A., \& Badami, P. S. (2009). Synthesis, physicochemical investigation and biological studies of Zinc (II) complexes with 1,2,4-Triazole Schiff base. Journal of the Iranian Chemical Society, 6(2): 259-270.

Bhattacharjee, C. R., Goswami, R. \& Mondal, P. (2012). Synthesis, reactivity, thermal, electrochemical and magnetic studies on iron (III) complexes of tetradentate Schiff base ligands. Inorganica Chimica Acta, 387: 86-92.

Cotton, F. A., Wilkinson, G., Murillo, C. A., \& Bochmann, M. (1999). Advanced Inorganic Chemistry. New York: John Wiley \& Sons. pp 598-702.

Cozzi, P. G. (2004). Metal-Salen Schiff base complexes in catalysis: Practical aspects. Chemical Society Reviews, 33: 410-421.

Crabtree, R. H. (1994), The Organometallic Chemistry of the Transition Metals. Second Edition. New York: John Wiley \& Sons. p. 487.

Ebsworth, E. A. V., Rankin, D. W. H. \& Cradock, S. (1987). Structural Methods in
Inorganic Chemistry. Oxford: Blackwell. p456.

Ershad, S., Sagathforoush, L. A., Nezhad, G. K., \& Kangari, S. (2009). Electrochemical behavior of $\mathrm{N}_{2} \mathrm{SO}$ Schiff-Base Co (II) complexes in non-aqueous media at the surface of solid electrode. Institute of Electrical and Electronics Engineers, 4: 846-854.

Kumar, S., Niranjan, M. S., Chaluvaraju, K. C., Jamakhandi, C. M., \& Kadadevar, D. (2010). Synthesis and antimicrobial study of some Schiff base of sulfonamides. Journal of Current Pharmaceutical Research, 1: 3942.

Li, H. Y., Li, J. W. \& Qiang, W. (2009). Bis $\{2-$ [3-(dimethylamino) propyliminomethyl]4,6-disulfanylphenolato cobalt(II). Acta Crystallography, 65: 1073.

Maity, D., Chattopadhyay, S., Ghosh, A., Michael, G.B. Drew, M. G. B. \& Mukhopadhyay G. (2011). Syntheses, characterization and X-ray crystal structures of a mono- and a penta-nuclear nickel (II) complex with oximato Schiff base ligands. Inorganica Chimica Acta, 365: 25-31.

Nishinaga, A., Yamada, T., Fujisawa, H., \& Ishizaki, K. (1988). Catalaysis cobalt Schiff complexes in the oxygenation of alkenes on mechanism of ketonization. Journal of Molecular Catalysis, 48: 249-264.

Ortiz, B., \& Park, S. M. (2000). Electrochemical and spectroelectrochemical studies of cobalt salen and salophen as oxygen reduction catalysts. Bulletin of Korean Chemical Society, 21(4): 405-411.

Park, S. S., Mathur, V. K., \& Planalp, R. P. (1998). Syntheses, solubilities and oxygen absorption properties of new cobalt (II) Schiff-base complexes. Polyhedron, 17(23): 325-330.

Patel, S. H., Pansuriya, P. B., Chhasatia, M. R., Parekh, H. M., \& Patel, M. N. (2008). Coordination chain polymeric assemblies of trivalent lanthanides with multidentate Schiff base synthetic, spectral investigation and thermal aspects. Journal of Thermal Analysis and Calorimetry, 91(2): 413-418. 
Przybylski, P., Huczynski, A., Pyta, K., Brzezinski, B. \& Bartl, F. (2009). Biological properties of Schiff bases and azo derivatives of phenols. Current Organic Chemistry, 13(2): 124-148.

Ran, X. G., Wang, L. Y., Cao, D. R., Lin, Y. C., \& Hao, J. (2011). Synthesis, characterization and in vitro biological activity of cobalt (II), copper (II) and zinc (II) Schiff base complexes derived from salicylaldehyde and D, Lselenomethionine. Applied Organometallic Chemistry, 25: 9-15.

Ray, A., Georgina M. Rosair, G. M., Pilet, G, Dede, B., Gómez-García, C. J., Signorella, S., Bellú, S. \& Mitra, S. (2011). Preferential azido bridging regulating the structural aspects in cobalt (III) and copper (II)-Schiff base complexes: Syntheses, magnetostructural correlations and catalytic studies. Inorganica Chimica Acta, 375: 20 30.

Salavati-Niasari, M., Salemi, P., \& Davar, F. (2005). Oxidation of cyclohexene with tertbutylhydroperoxide and hydrogen peroxide catalysted by copper (II), nickel (II), cobalt (II) and mangan (II) complexes of $N, N^{\prime}$ bis-(a-methylsalicylidene)-2,

2 dimethylpropane-1,3-diamine, supported on alumina. Journal of Molecular Catalysis A: Chemical, 238: 215-222.
Solomons, T. W. G., \& Fryhle, C.B. (2011). Organic Chemistry. Tenth Edition. Asia: John Wiley \& Sons. p751.

Tarafder, M. T. H., Khoo T. J., Crouse, K. A., Ali, A. M., Yamin, B. M. \& Fun, H. K. (2002). Coordination chemistry and bioactivity of $\mathrm{Ni}^{2+}, \mathrm{Cu}^{2+}, \mathrm{Cd}^{2+}$ and $\mathrm{Zn}^{2+}$ complexes containing bidentate Schiff bases derived from $S$-benzyldithiocarbazate and the X-ray crystal structure of bis $[S$ benzylb- $N$-(5-methyl-2-furylmethylene) dithiocarbazato] cadmium (II), Polyhedron, 21: 2683-2690.

Turan, N., \& Sekerci, M. (2009). Synthesis and characterization of Co (II), Ni (II), Cd (II) and $\mathrm{Cu}$ (II) complexes of bis- Schiff base obtained from 1, 8- diaminonaphthalene. Journal of the Chemical Society of Pakistan, 31(4), 564-568. 